\title{
A Combined AHP-PROMETHEE Approach for Intelligent Risk Prediction of Leak in a Storage Tank
}

\author{
F. Ikwan ${ }^{1 *}$ D. Sanders ${ }^{2}$, M. Haddad ${ }^{1}$ \\ 1. Systems Engineering Research Group, University of Portsmouth, United Kingdom \\ 2. Systems Engineering Research Group Anglesea Building Anglesea Road, University of Portsmouth, \\ United Kingdom
}

\begin{abstract}
This paper describes the use of the Analytic Hierarchy Process (AHP) and Preference Ranking Organization Method for Enrichment Evaluation (PROMETHEE) method for predicting the risk of leakage in a storage tank. This is the first time AHP and PROMETHEE have been used in this way. Important decisions about day to day operations are continually made in a petroleum environment. Storage tanks in refineries contain large volumes of flammable and hazardous liquids. Decision processes need to evaluate and select alternatives with a higher probability of resulting in a hazard, among many different alternatives. The new model described in this paper will aid decision-makers to predict which tank is likely to develop a leak and determine what criteria (source of risk) could result in a leak. Although the case study deals with a specific risk prediction problem, the combination of AHP and PROMETHEE methods can be applied to other decision problems.
\end{abstract}

Keywords: AHP; Decision making; Multi-criteria analysis; PROMETHEE; Risk prediction

\section{Introduction}

This paper describes the use of the Analytic Hierarchy Process (AHP) and Preference Ranking Organization Method for Enrichment of Evaluation (PROMETHEE) method for predicting the risk in a storage tank. This is the first time AHP and PROMETHEE have been used as a hybrid model in this way.

Hazardous and flammable liquids in refineries are often in large volumes. Any form of accident could often lead to millions of dollars in property loss, interruption in daily operations, accidents, lawsuits, assets devaluation, or even company bankruptcy [1]. Decisions about day to day operations are continuously made in a petroleum environment. Decision making is often considered as a process where alternatives are analyzed to pick a choice or a course of action to meet set aims and goals [2]. These decisions impact risks associated with accidents or incidents.

This paper considers the evaluation of choices and selection of the alternative with a higher probability of resulting in a hazard (leak) among different alternatives. The solution tothis multi-criteria decision problem helps decision-makers to use labor and time efficiently and

\footnotetext{
* Corresponding Author Email: favour.ikwan@myport.ac.uk
}

productively. This could better meet the needs and goals of a company or organization.

Different methods have been adopted to aid decision problems. Examples of multi-criteria decision problem methods include the Analytic Hierarchy Process (AHP) [3], Analytic Network Process (ANP) [4], Technique for Order Preference by Similarity to Ideal Solution (TOPSIS) [5], Multi-Criteria Optimization and Compromise Solution (VIKOR) [6], Elimination and Choice Expressing Reality (ELECTRE) [7] and Preference Ranking Organization Method for Enrichment Evaluation (PROMETHEE) [8].

The research described in this paper created a new hybrid model for predicting risk by combining two methods, AHP and PROMETHEE. A model with 4 criteria divided into 12 sub-criteria was created to select the storage tank with the highest probability of a leak. AHP was applied to determine the weights of the criteria, then the tank with the highest probability of a leak was determined via PROMETHEE by using the weights calculated by AHP.

\section{AHP and PROMETHEE}

AHP and PROMETHEE are MCDM methods that have been used in recent oil and gas studies. Ying et.al used 
AHP to investigate the risk of an oil spill from a port tank region based on a fuzzy complete evaluation [9].

AHP and TOPSIS were applied by Bing et.al to plant preference for phytoremediation of oil-polluted soils in shale gas and oil terrains [10]. PROMETHEE method was presented by Brans and Vincke as an effective MCDM mechanism for ranking projects [11]. AHP and PROMETHEE are briefly described in the next two sub-sections.

\section{AHP}

AHP was developed by Thomas L. Saaty in 1971-1975 [3]. It represented a mathematical expression for humans' perception of complex problems in a hierarchical model. Saaty recognized AHP as an effective method that allowed decision-makers to understand the relationship between goals, criteria, and alternatives [12]. Saaty and Vargas described AHP as a model based on pairwise comparisons, using expert judgment to design priority scales and create mathematical models of possible solutions [13]. The aim of developing AHP was to support analytical decisions where several alternatives were assessed with relevance to several criteria [13]. Ishizaka \& Labib described how decision-makers could use AHP to solve a problem with various contradictory criteria by cutting down a multifaceted situation into easier sub-situations then combining the results of all sub-situations into one result [14]. AHP used proficient assessments to develop priorities and implement pairwise comparisons to ascertain how significant one alternative was to another concerninga specific criterion [15]. A simple AHP model composed of three levels can be seen in Figure 1.

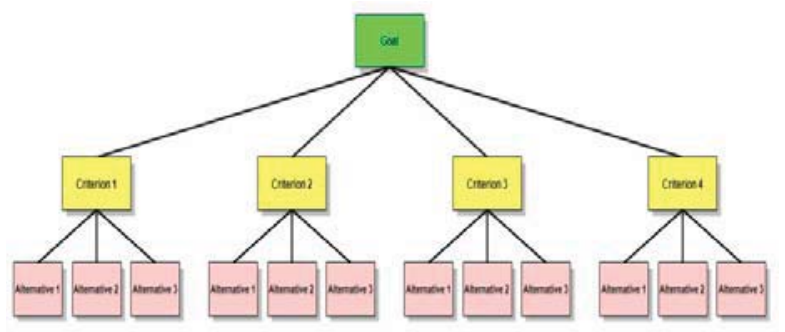

Figure 12. Analytical Hierarchy Process hierarchy model [4]

The first level of the hierarchy shown in Figure 1 defines the purpose of the decision process, the second level describes the collection of criteria by which alternatives were evaluated and the last level shows the set of alternatives considered for the problem [13].

The AHP application can be described with the following systematic approach [16]:

1. Problem is formulated hierarchically. The goal, main criteria, sub-criteria, and alternatives should be defined.

2. Pairwise comparisons and relative importance are derived.
3. Consistency of pairwise comparison matrices is checked. If the consistency ratio (CR) is equal to or less than 0.1 , the comparisons are considered consistent.

4. Priorities of alternatives are calculated by combining the weights of criteria and ratings of alternatives. The weight of each criterion is derived using pairwise comparisons

Saaty proposed a consistency index (CI) and calculated it using Equation (1) [3]:

$C I=\frac{\lambda^{\max }-n}{n-1}$

Where $\lambda \max =$ maximal eigenvalue.

The Consistency Ratio (CR) was given by: $\mathrm{CR}=\mathrm{CI} / \mathrm{RI}$, where RI was the Random Index (RI) [3].

\section{PROMETHEE}

PROMETHEEstands for Preference Ranking Organization Method for Enrichment of Evaluation, was developed by Brans [8] and further developed by Brans and Vincke [17].PROMETHEE methods are outranking methods, where deterministic pairwise comparisons and an ordinal preference structure are used to provide a complete ranking (PROMETHEE II) or partial ranking (PROMETHEE I) of a discrete collection of alternatives.

The application of PROMETHEE required weights for criteria and a preference function representing each criterion [18]. An outranking chart was constructed using a preference index [17]. Brans and Maraschal [11] listed these functions as Usual criterion, U-shape criterion, V-shape criterion, Level criterion, V-shape with indifference criterion, and Gaussian criterion functions as shown in Figure 2.

PROMETHEE methods applied the following steps:

- Define the problem.

- Define a set of criteria.

- Classify information between criteria (criteria weights).

- Classify Information within criteria (preference functions and pairwise comparisons).

- Classify a set of alternatives.

- Asses total score of alternatives. 


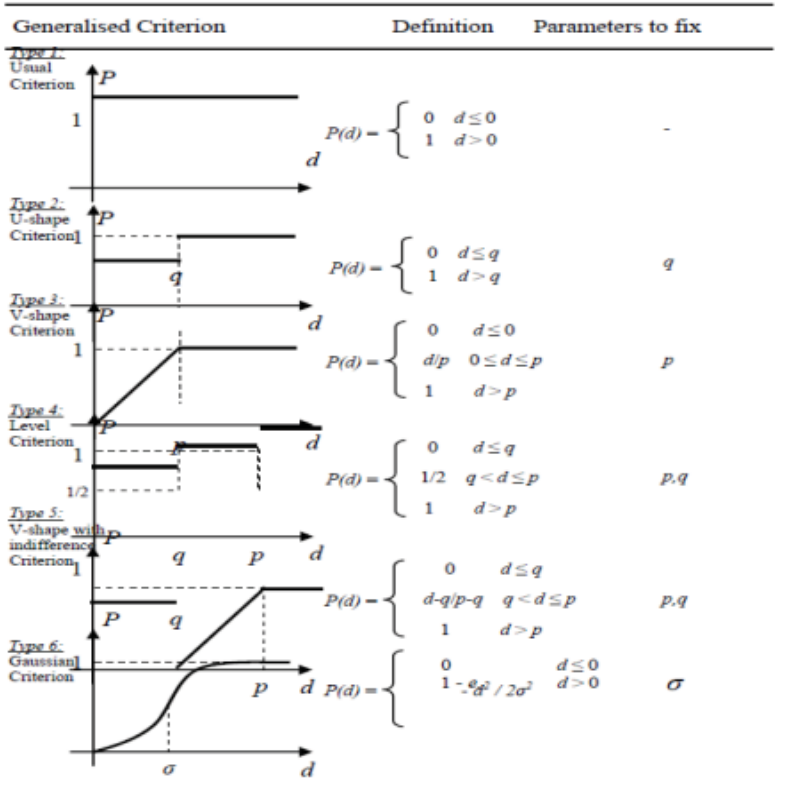

Figure 13. Preference Functions used in PROMETHEE methods [17].

Where,

q: Threshold of indifference.

p: Threshold of strict preference.

$\sigma$ : intermediate value between $q$ and $p$.

Aggregated Preference Indices were calculated using Equations (2 and 3) [11]

Let a,b $\in A$ and:

$\pi(a, b)=\sum_{j=1}^{n} P_{J}(a, b) \cdot W_{j}$

$\pi(a, b)=\sum_{j=1}^{n} P_{J}(b, a) \cdot W_{j}$

$\pi(a, b)$ expresses the degree by which alternative ' $a$ ' is preferred to alternative ' $b$ ' over all the set of criteria considered and $\pi(b, a)$ how alternative ' $b$ ' is preferred to alternative ' $a$ '. Consequently $\pi(a, b)$ and $\pi(b, a)$ are usually positive. The following properties hold for all alternative 'a', 'b'.

$\pi(\mathrm{a}, \mathrm{a})=0 . \quad 0 \leq \pi(\mathrm{a}, \mathrm{b}) \leq 1 \quad 0 \leq \pi(\mathrm{b}, \mathrm{a}) \leq 1.0$ $\leq \pi(\mathrm{a}, \mathrm{b})+\pi(\mathrm{b}, \mathrm{a}) \leq 1$.

$\pi(\mathrm{a}, \mathrm{b}) \approx 0$ weak global preference of a over $\mathrm{b} . \pi(\mathrm{a}, \mathrm{b})$

$\approx 1$ strong global preference of a over $b$.

Brans calculated positive and negative outranking flows using Equations (4 and 5):
Positive outranking flow:

$\Phi^{+}(\mathrm{a})=\frac{1}{\mathrm{n}-1} \sum_{\mathrm{x} \in \mathrm{A}} \pi(\mathrm{a}, \mathrm{x})$

Negative outranking flow:

$\Phi^{-}(\mathrm{a})=\frac{1}{\mathrm{n}-1} \sum_{\mathrm{x} \in \mathrm{A}} \pi(\mathrm{x}, \mathrm{a})$

\section{Integration of AHP and PROMETHEE.}

AHP is a decision-making method that could be used as an assessment tool, which determines the degree of importance of alternatives by pairwise comparisons. PROMETHEE is an outranking decision-making method.

Kasim et.al (2016) [19] listed some of the strong and weak points of the methods as follows:

AHP is easy to use for handling complex problems. If the number of criteria exceeds seven, problems get more complicated in PROMETHEE.

There is no fundamental method for calculating weights in PROMETHEE. This process was achieved analytically in AHP. The relative importance is understood better by pairwise comparisons.

AHP has sub-systems that could generate more data to work on while in PROMETHEE, it is possible to solve with fewer data.

The results from PROMETHEE can be explained using better visual representations and the effect of each criterion on an alternative can be understood more easily.

Geometrical Analysis for Interactive Aid (GAIA) techniques also help with visualization of the analysis.

The weight of a criterion in PROMETHEE and AHP is a measure of how important it is concerning other criteria. The Weight of a criterion in PROMETHEE is any positive number that depicts the criterion relative importance. Visual PROMETHEE weights are automatically normalized so that their sum is equal to 1 .

PROMETHEE has no known fundamental scale of measurement to validate the comparison judgments. The fundamental scale of values to describe the intensities of judgments by Satty\&Vagas was authenticated for effectiveness, not only by several people in many applications but also through theoretical validation of what scale might be used in comparing homogeneous elements [12].

In the work presented in this paper, the weights of each criterion in AHP are derived through pair wise comparisons. Weights of criteria and sub criteria were evaluated in AHP and then used in PROMETHEE. In that way, risk could be predicted by combining both approaches to rank the alternatives.

The new AHP-PROMETHEE approach has six steps. These are: 
- Defining the problem.

- Defining the criteria, sub-criteria, and alternatives.

- Formation of the hierarchy structure using AHP.

- Calculation of weights of criteria using AHP.

- Determining the calculation table and preference functions for PROMETHEE outcome.

- Full ranking with PROMETHEE II.

\section{The leak in a storage tank.}

The problem considered in this paper was to predict which tank was most likely to leak. The first step was to identify the causes that could lead to a leak in a storage tank [20]. 4 main criteria divided into 12 sub -criteria were identified (Figure 3). They are:

- Level control failure: sensor level failure, valve shut off response failure, incorrect alarm response, and acoustic signal.

- Operator failure: fatigue defect, operator distracted.

- Loss of leak tightness: tank breaking, corrosion, insufficient revisions, reenforcement breaking.

- Environmental effect: terrorist attack, earthquake.

The alternatives to be evaluated were four storage tanks: 1, 2, 3, and 4 .

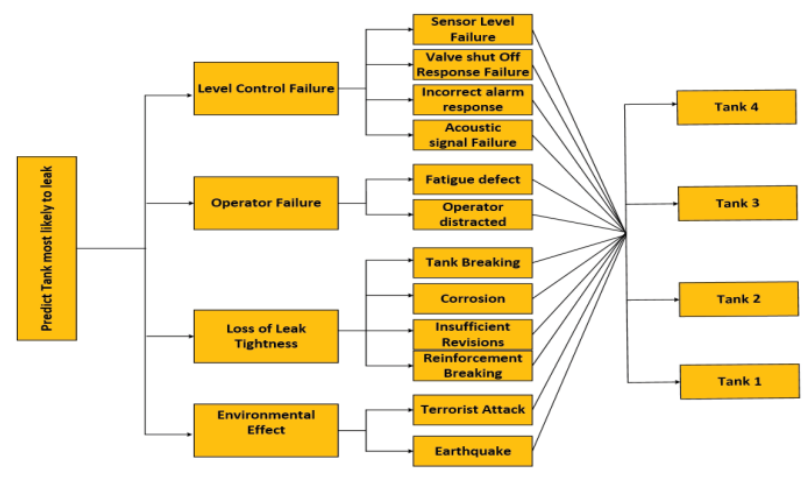

Figure 14. AHP Hierarchy model to predict a leak in a tank

\section{Determining criteria weights}

The weights of the main and sub criteria were ascertained using AHP. Frequency of events or undesired events needed to be determined. Frequencies were determined using data from fuel storage research $[21,22]$. The frequency of the main criteria can be seen in Table 1. It was scaled using 1-9 where 1 is the least important and 9 is the most important.

Table 4. Frequency of main criteria

\begin{tabular}{ccc}
\hline Main criteria & Frequency & Scale of 1-9 \\
\hline Level control failure & 0.72 & 9 \\
Operator failure & 0.0018 & 3 \\
Loss of leak tightness & 0.012 & 6 \\
Environmental Effect & 0.000725 & 1 \\
\hline
\end{tabular}

Using the scale $1-9$ where number 1 suggested that the criterion under consideration was of equal importance and a value of 9 suggested that the criterion under consideration was of extreme importance compared to other criterion, the pairwise comparison of the main criteria is shown in Table 2. The reciprocal of the assigned value was assigned to the less important criterion and perfect consistency between criteria was ascertained.

Table 5. Matrix Pair Wise Comparison of Main Criteria

\begin{tabular}{ccccc}
\hline $\begin{array}{c}\text { Main } \\
\text { Criteria }\end{array}$ & $\begin{array}{c}\text { Level } \\
\text { control } \\
\text { failure }\end{array}$ & $\begin{array}{c}\text { Operator } \\
\text { failure }\end{array}$ & $\begin{array}{c}\text { Loss of } \\
\text { leak } \\
\text { tightnes } \\
\text { s }\end{array}$ & $\begin{array}{c}\text { Environmental } \\
\text { Effect }\end{array}$ \\
\hline $\begin{array}{c}\text { Level } \\
\text { control } \\
\text { failure }\end{array}$ & 1 & 3 & 1.5 & 9 \\
$\begin{array}{c}\text { Operator } \\
\text { failure }\end{array}$ & 1 & 0.5 & 3 \\
$\begin{array}{c}\text { Loss of leak } \\
\text { tightness }\end{array}$ & & 1 & 6 \\
$\begin{array}{c}\text { Environmen } \\
\text { tal Effect }\end{array}$ & & & 1 \\
\hline
\end{tabular}

The data in Table 2 were processed to determine the weights of the criteria. The consistency index which is the index of the consistency of judgments across all pairwise comparisons was also determined using the method in [23]. Pairwise comparison, weights, and consistency index for each sub-criteria were determined. AHP was used to calculate the sub-criteria weights from the main criteria weights (Table 3). This was achieved by multiplying the main criteria priority vector by its sub-criteria priority vector. Table 3 shows the weights of the criteria and sub-criteria. According to Table 3 "incorrect alarm response" was the most important criterion and "earthquake" the least important criterion for this study.

Table 6. Calculating weights of sub-criteria according to weights of the main criteria

\begin{tabular}{|c|c|c|c|c|c|}
\hline $\begin{array}{c}\text { Main } \\
\text { Criteria }\end{array}$ & $\begin{array}{c}\text { Priority } \\
\text { vector } \\
\%\end{array}$ & Sub Criteria & $\begin{array}{c}\text { Priority } \\
\text { vector } \\
\%\end{array}$ & $\begin{array}{c}\text { New } \\
\%\end{array}$ & $\begin{array}{c}\text { New } \\
\text { Ran } \\
k\end{array}$ \\
\hline \multirow[t]{3}{*}{$\begin{array}{c}\text { Level } \\
\text { Control } \\
\text { Failure }\end{array}$} & 47.37 & $\begin{array}{c}\text { Sensor } \\
\text { Level } \\
\text { Failure }\end{array}$ & 25.8 & 12 & 10 \\
\hline & & $\begin{array}{l}\text { Valve Shut } \\
\text { Off } \\
\text { Response } \\
\text { Failure }\end{array}$ & 21.6 & 10.2 & 8 \\
\hline & & In Correct & 34.1 & 16 & 11 \\
\hline
\end{tabular}




\begin{tabular}{|c|c|c|c|c|c|}
\hline & & $\begin{array}{c}\text { Alarm } \\
\text { Response }\end{array}$ & & & \\
\hline & & $\begin{array}{l}\text { Acoustic } \\
\text { Signal } \\
\text { Response } \\
\text { Failure }\end{array}$ & 18.5 & 8.5 & 6 \\
\hline \multirow[t]{2}{*}{$\begin{array}{c}\text { Operator } \\
\text { Failure }\end{array}$} & 15.78 & $\begin{array}{l}\text { Fatigue } \\
\text { Defect }\end{array}$ & 33.3 & 5.2 & 3 \\
\hline & & $\begin{array}{l}\text { Operator } \\
\text { Distracted }\end{array}$ & 66.6 & 10.4 & 9 \\
\hline \multirow{4}{*}{$\begin{array}{c}\text { Loss of } \\
\text { Leak } \\
\text { Tightness }\end{array}$} & 31.57 & $\begin{array}{c}\text { Tank } \\
\text { Breaking }\end{array}$ & 24.9 & 7.84 & 5 \\
\hline & & Corrosion & 30.0 & 9.45 & 7 \\
\hline & & $\begin{array}{l}\text { Insufficient } \\
\text { Revisions }\end{array}$ & 19.9 & 6.26 & 4 \\
\hline & & $\begin{array}{c}\text { Re- } \\
\text { Enforcemen } \\
\text { t Breaking }\end{array}$ & 24.9 & 7.84 & 5 \\
\hline \multirow{2}{*}{$\begin{array}{c}\text { Environ } \\
\text { mental } \\
\text { Effect }\end{array}$} & 5.26 & $\begin{array}{l}\text { Terrorist } \\
\text { Attack }\end{array}$ & 56.5 & 2.97 & 2 \\
\hline & & Earthquake & 43.4 & 2.28 & 1 \\
\hline
\end{tabular}

\section{Applying Visual PROMETHEE}

The project alternatives were sequenced via PROMETHEE after calculating weights in AHP. Visual PROMETHEE was used for analysis. The data for the model with criteria and alternatives are shown in Figure 4. Random numbers between $1-9$ were generated to create test cases for alternatives concerningthe 12 subcriteria. The numbers for the alternatives were randomly generated. The preference was set to "min". The preference functions for each criterion were: The upper limit of the sensor level valve failure criteria, the valve shut off response, incorrect alarm response, were assumed to be $4 \mathrm{ft}, 5 \mathrm{ft}, 4$, and a V-type function was used for these criteria.For the analysis of the other criteria, a Usual function was used.

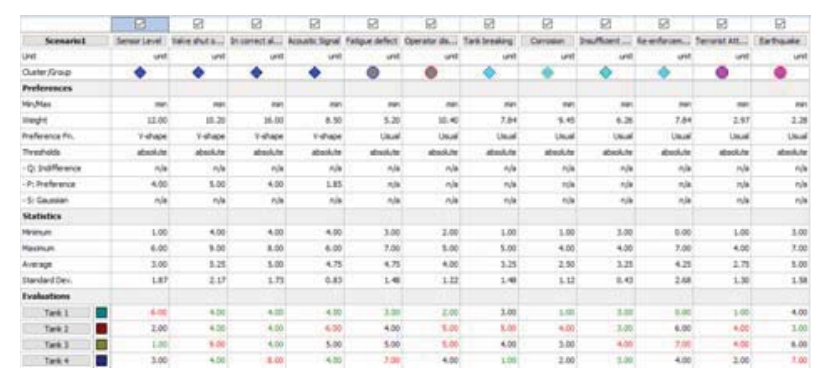

Figure 15. Screenshot of visual PROMETHEE used for the problem considered in this paper.

\section{Full Ranking with PROMETHEE II}

Full ranking combining positive and negative priority values was performed by PROMETHEE II. The resulting ranking of the negative, the positive and the net flow (priority) values of alternative projects ordered in Table 4 showed that" Tank 1" was the first order (least likely to develop a leak), "Tank 4" was the second and "Tank 2" was the third-best alternatives and "Tank 3"has the highest probability to leak. This ranking was important as it determined alternatives with minimum risk.

Table 7. PROMETHEE Flow Table

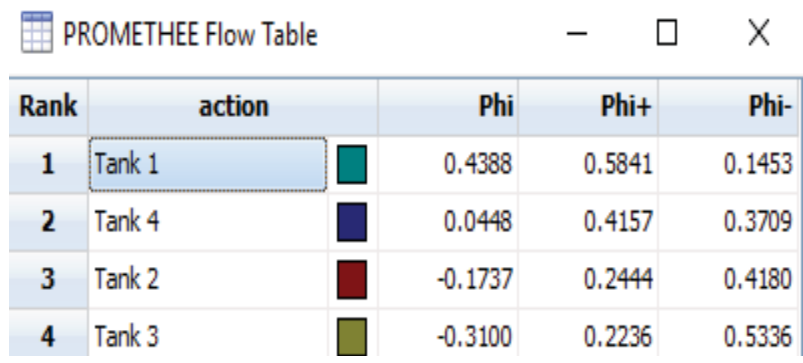

\section{The Factors Affecting}

\section{The Worst Alternative}

Figure 5 shows a disaggregated representation of the strengths and weakness of an alternative or the unicriterion net flow scores for Tank 3. A bar is drawn with as much number of criteria for each alternative. Each slice corresponds to a contribution of the criteria onto the Phi net flow score and was the net outranking flow for each alternative, considering the weight of the criterion. The -ve Phi score (lower section) shows weakness and the +ve Phi score (upper region) shows strengths. PROMETHEE II complete ranking results predicted that Tank 3 was most likely to leak. Tank 3 has +ve and -ve slices, meaning it performed better on some criteria and worse on other criteria. Figure 5 shows the criteria, showing the strengths of Tank 3 which were sensor failure and incorrect alarm response. Other criteria were weaknesses. Since Tank 3 performed good on only two criteria and did not perform good on all other criteria, then Tank 3 would have the highest risk to leak.

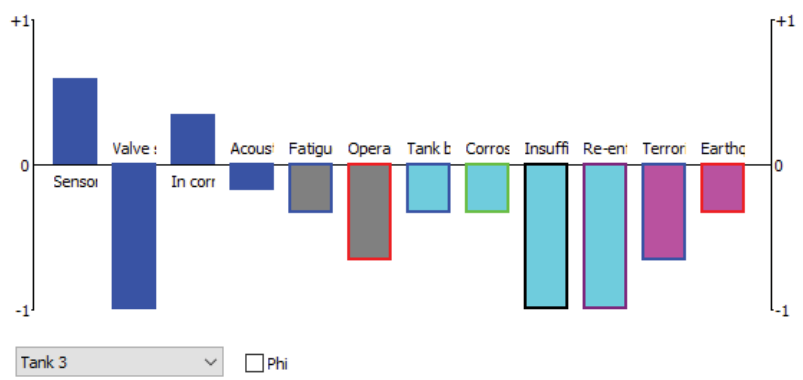

Figure 5. The criteria contributing to Tank 3. 


\section{The geometrical GAIA plane}

The geometrical GAIA plane as shown in Figure 6 shows the dispersion of criteria depending on the values of alternatives. Vectors represent the criteria and the alternatives are represented by squares. The length of a vector for a specific criterion gives the effect of that criterion on the outcome of the problem. The resulting GAIA plane also shows the quality value for the analysis. The accuracy of the analysis gets higher as the quality valuegets closer to $100 \%$. Quality values above $75 \%$ can be accepted as accurate and below $60 \%$ is inaccurate. If results had a quality value below $60 \%$, the model and calculations should be reviewed and revised [11].The quality value in Figure 6 was calculated as $88.8 \%$, which meant that $12.2 \%$ of overall data was lost. This loss could have been due to the use of nonquantitative measures for some criteria.

Vector pi (decision axis) was used to choose the top alternative and the decision-makers should choose the alternatives on the pi axis [24]. In Figure 6, "Tank 1" was in the same direction as the pi axis which was consistent with the PROMETHEE II results.
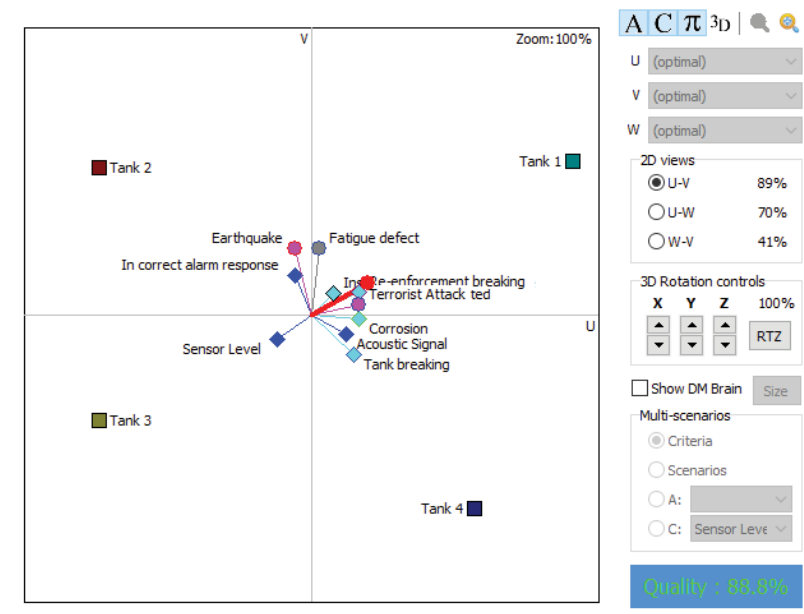

Figure 6. Dispersion of alternatives and criteria in the geometrical plane.

\section{Conclusion}

This paper described a new hybrid model created by combining two decision methods: AHP and PROMETHEE. The new model was used to help decision makers predict risk in a storage tank.

A model with 4 criteria divided into 12 sub-criteria was created to select the storage tank with the highest probability of a leak. AHP was used for calculating criteria weights. Then the tank with the highest probability of leaking was predicted using PROMETHEE with criteria weights calculated in AHP.

The main aim ofusing this hybrid method was to take advantage of these two efficient methods to predict and minimize risk. Pairwise comparison of the criteria with AHP method gave a coherent perception of the weights ofthe criteria and the PROMETHEE method defined a preference function which varied for some criteria, providing a complete ranking of storage tank most likely to leak.

This paper applied the PROMETHEE II method with type 1 preference function "usual criterion", other types of preference functions might show different behavior and could enhance the stability of the method." Full ranking combining positive and negative priority values was performed by PROMETHEE II. PROMETHEE II results predicted that Tank 3 was most likely to leak. It also showed the strengths and weaknesses of each tank. The strengths and weaknesses of each tank predicted what criteriato focus on each tank. The quality value of the analysis was calculated to be $88.8 \%$.

Results could aid operators mitigate or avoid potential process hazards and make timely decisions. Immediate corrective measures to reduce or eradicate the occurrence of the risk of leak accident of the tank should be taken.

Future work will include the use of machine learning techniques and artificial neural networks to predict risk [25]. The sample learning for the input could be the data set covering the system faults listed as criteria or/and subcriteria. The output could imply the degree of a system fault which could be used to evaluate system risk and allow critical decisions. The decisions could reduce anomalies, enhance monitoring, and decrease threat levels [26, 27, 28].Real-world problems with a larger number of alternatives (storage tanks), criteria (other major causes of the leak) and sub-criteria will be considered.Sensitivity analysis will be performed on both performance measures and criteria weights to provide a better understanding of a problem. Monte Carlo simulation and other approaches will be used to model uncertainty in more than one input factor at the same time to provide a better understanding of the problem

\section{Declaration of Conflicting Interests}

The Author(s) declare(s) that there is no conflict of interest.

\section{References}

[1] James, C., and Cheng-Chung, L., "A study of storage tank accidents," Journal of Loss Prevention in the Process Industries 19(1): pp. 51-59, 2009.

[2] Ikwan, F., "Reducing energy losses and alleviating risk in petroleum engineering using decision making and alarm systems" Journal of computing in systems and engineering, ISSN 1472-9083: pp. 422-429, 2018.

[3] Saaty, T.L., "The analytic hierarchy process - what it is and how it is used," Mathematical modelling, 9 (35): pp. 161-76 (1987).

[4] Saaty, T.L., "How to make a decision: the analytic hierarchy process," Interfaces, 24(6): pp.19-43,1994.

[5] Huang, C., Tong, I., Chang, W. and Yeh, C., "A twophase algorithm for product part change utilizing AHP 
and PSO," Expert Systems with Applications: pp 38, 2011.

[6] Opricovic, S., Multicriteria optimization of civil engineering systems (in Serbian) Belgrade: $\mathrm{PhD}$ Thesis, Faculty of Civil Engineering: pp. 302, 1998.

[7] Roy, B., "Classement et choixenprésence de points de vue multiples," RAIRO-Operations ResearchRecherche Opérationnelle, (2): pp. 57-75,1968.

[8] Brans, J.P., "Lingenierie de la decision. Elaboration d'instrumentd'aide a la decision. Methode PROMETHEE. Colloqued'Aide a la Decision. Universite Laval, Quebec, Canada; pp.183-213, (1982)

[9] Ying, L., Wei, W., BingXin, L. and Xin, Z., "Research on oil spill risk of port tank zone based on a fuzzy comprehensive evaluation," Aquatic Procedia, (3): pp.216-223, 2015.

[10] Bing, W., Hong, L. and Hong, Y., "Application of AHP, TOPSIS, and TFNs to plant selection for phytoremediation of petroleum-contaminated soils in shale gas and oil fields," Journal of Cleaner Production: pp.13-22, 2019.

[11] Brans, J. P., Vincke, P. H. and Mareschall, B., "How to select and how to rank projects: The PROMETHEE method," European Journal of Operational Research, 14: pp. 228-238, 1986.

[12] Saaty, T.L., "Decision making with the analytic hierarchy process," International journal of services sciences, 1(1): pp.83-98, 2008.

[13] Saaty, T.L. and Vargas, L.G., "Models, methods, concepts \& applications of the analytic hierarchy process," Springer Science \& Business Media, 175(2): pp.1-342, 2012

[14] Ishizaka, A. and Labib, A., "Analytic hierarchy process and expert choice: Benefits and limitations" $O R$ Insight, 22(4), pp.201-220, 2009.

[15] Haddad, M. and Sanders, D., "Deep Learning Architecture to Assist with Steering a Powered Wheelchair," IEEE Transactions on Neural System and Rehabilitation Engineering, Accepted and in Press, 2020

[16] Saaty, T.L., Fundamentals of Decision Making and Priority Theory with the Analytic Hierarchy Process, RWS Publications; 2000.

[17] Brans, J.P and Vincke, P.H., "A preference ranking organization method: The PROMETHEE method," Management Science, 31: pp. 647-65, 1985.

[18] Macharis, C., and Springael, J., "PROMETHEE and AHP: The design of operational synergies in multicriteria analysis. Strengthening PROMETHEE with ideas of AHP," European Journal of Operational Research,153: pp 307-317, 2004.

[19] Kasım., B, Sari, T. and Koçdağ, V., "A combined AHP-PROMETHEE approach for project selection and a case study in the Turkish textile industry," EEuropean Journal of Business and Social Sciences, 5(1): pp. $202-216,2016$.

[20] Ikwan F. et al., Intelligent risk prediction of storage tank leakage using an Ishikawa diagram with probability and impact analysis. In: Arai K., Kapoor S., Bhatia R. (eds) Intelligent Systems and Applications. IntelliSys 2020. Advances in Intelligent Systems and Computing, Springer, Cham; vol 1252, 2021.

[21] Tongyuan, L., Chao, Wu. and Lixiang, D., "Fishbone diagram and risk matrix analysis method and its application in the safety assessment of natural gas spherical tank," Journal of Cleaner Production, 174: pp. 296-304, 2017

[22] José, L., Carmen, G-C., Cristina, G-G., and Piedad, B., "Risk analysis of a fuel storage terminal using HAZOP and FTA" International Journal of Environmental research and public health, 14(17): pp. 705, 2017.

[23] Saaty, T.L., "Decision Making - The Analytical Hierarchy and Network Processes (AHP/ANP)," Journal of Systems Science and Systems Engineering, 13(1): pp. $1-35,2004$.

[24] Wang, J.J. and Yang, D.L., "Using a hybrid multicriteria decision aid method for information systems outsourcing," Computers \& Operation Research, 34(12): pp. 3691-3700, 2007.

[25] Haddad, M. and Sanders, D., "Artificial Neural Network approach for business decision making applied to a corporate relocation problem". Archives of Business Research, 8(6): pp.180-195, 2020.

[26] Omoarebun, P., "Disaster risk reduction in petroleum engineering". Journal of Computing in Systems Engineering. ISSN 1472-9083. Pp. 499, 2018.

[27] Omoarebun, P., Sanders, D., Haddad, M., Hassan, M., Tewkesbury, G., Giasin, K., "An intelligent monitoring system for crude oil distillation column". 2020 IEEE. $10^{\text {th }}$ International Conference on Intelligent Systems (IS). Pp. 159, 2020.

[15] Omoarebun P. et al., Intelligent Monitoring Using Hazard Identification Technique and Multi-sensor Data Fusion for Crude Distillation Column, In Arai K., Kapoor S., Bhatia R. (eds) Intelligent Systems and Applications. IntelliSys 2020. Advances in Intelligent Systems and Computing, Springer, Cham; vol 1252, 2021 